\title{
CONSTRUCTIVIST THEORY AS A FOUNDATION FOR THE UTILIZATION OF DIGITAL TECHNOLOGY IN THE LIFELONG LEARNING PROCESS
}

\author{
Saif MOHAMMED \\ ORCID: 0000-0002-2414-7133 \\ Faculty of Humanities and Social Sciences \\ University of Szeged \\ Szeged, HUNGARY \\ Dr. Laszlo KINYO \\ ORCID: 0000-0002-3549-4018 \\ Faculty of Humanities and Social Sciences \\ University of Szeged \\ Szeged, HUNGARY
}

Received: 19/04/2020 Accepted: 04/06/2020

\begin{abstract}
Lifelong learning, with the help of digital technology, possesses the capacity to offer individual significant advantages to individual learners. This paper examines both the diverse approaches to lifelong learning and the digital tools available to promote these strategies. The paper contains a review of some of the main articles pertaining to the fields of constructivism, digital technology, and the process of lifelong learning. Specifically, the authors intend to critically evaluate the utilization of rapidly developing digital technologies, such as computers, tablets, and mobile devices, within lifelong learning and their role as tools in promoting access to both practical and theoretical knowledge and in facilitating the communication of ideas within a global network, as per the constructivist approach. Hence, this article relies upon a specific definition of lifelong learning and an exploration of the notional foundation of what comprises lifelong learning and the environment in which their knowledge acquisition occurs. Thus, a framework for the present research is established wherein peer-reviewed studies concerning the use of social media by lifelong learners is explored, and extrapolating from the dual tenets of professional development and adult learning theory. Moreover, the authors additionally examine approaches to the notion of PLEs (personal learning environments) and PLNs (personal learning networks) as related to the selection of relevant lifelong learning strategies. The discussion is exemplified by cases ranging from video platforms to blogs and is simultaneously multidisciplinary and spanning diverse fields. Each example has applicability for lifelong learning and represents the characteristics of constructivism and its support within a web-based learning environment. It is thereby suggesting that effective and meaningful strategies supportive of the lifelong learning lifestyle can be achieved via welldesigned PLEs and PLNs.
\end{abstract}

Keywords: Lifelong learning, constructivism, digital technology, personal learning environment, professional learning network. 


\section{INTRODUCTION}

In recent decades the education system has undergone radical alteration. This is no surprise since formal education has been repeatedly reinvented over the centuries, each time rendering itself responsive to the demands of the period. In contemporary society, characterized as it is by constant and rapid change, formal education has emerged as inadequate in both content and format to satisfy the requirements of its modern society. With the quantity of available information expanding at a seemingly exponential rate, the quality of knowledge transmission appears more than a little deficient. One way in which this failing has begun to be addressed is the growing interest in lifelong learning via a process which combines formal, informal, and non-formal instruction. Lifelong learning, sometimes referred to as career-long learning, reaches beyond mere formal education or training and extends throughout the individual learner's life (Burman et al., 2014).

The need to improve the skills and competencies of the working population has been influenced by two recent global developments, the rapid pace of technological change and globalization. This changing circumstance has led to the need for everyone to incorporate lifelong learning into their career plan as skills should be enhanced, updated, and augmented whenever the opportunity arises. Adapting to change is a skill in itself, but it is rewarded by life being enriched by the prospect of learning new things and the fulfilment that results from the natural desire to learn and evolve (Laal \& Salamati, 2012).

Not only is the expertise acquired via formal education no longer sufficient for business needs, but it is also inadequate to meet the demands of wider society. Nowadays, advances in the digital device facilitate ease of access to quality, structured learning in accordance with multimedia and constructivist learning approaches wherein multiple tools permit access to comprehensive content with on-demand availability and no requirement for additional resource provision and organized body or association (Pureta, 2015).

In other words, knowledge exists beyond the confines of the curriculum of specific professions or academic fields, and the objective of lifelong learning is to comprise an addendum to existing formal systems with their inherent and well-established weaknesses, at least until a more satisfactory formal educational system is devised. Moreover, it is crucial to continuing professional development in almost all occupational arenas (Pureta, 2015).

By 2007, the United States Bureau of Statistics was already predicting a 10 million shortfall in the number of workers who would be equipped with appropriate skills in 2010 (Thompson, 2007). In the same year, a reported $40 \%$ of employers were expressing acute shortages in skilled labour. It is vital that any worker seeking advancement in their career or socioeconomic mobility acquire new knowledge and expertise. Likewise, businesses in search of an increase in productivity and profits must take steps to acquire a suitably skilled workforce. To achieve these objectives, a new philosophy of learning, founded on principles of extended and continuous knowledge acquisition is required. Hence, it is fair to say that lifelong learning can bestow both social and economic advantages on workers while satisfying the needs of employers too (Johnson, 2010).

\section{ADULT EDUCATION}

Adult education constitutes a well-established educational sub-discipline wherein adults participate in organized and extensive learning activities designed to modify their existing "knowledge, attitudes, values, and skills" (Darkenwald \& Merriam, 1982).

Despite the large and growing numbers of educational institutions, there remains a shortfall such that many who wish to expand their knowledge and skills find their needs are not fulfilled by these educational establishments. Moreover, the suitability of some formal educational institutions for certain educations is questionable. Certain training needs also appear quite alien to these institutions, and, as a consequence, adult education is frequently committed by the workplace offers training programs organized with the assistance of adult education professionals (Kumar, 2012).

According to Merriam and Caffarella (1999), adult learning is heavily influenced by its socio-cultural setting and is, therefore, best appreciated by an evaluation of this context. The substance of learning, the options available, and the mode through which knowledge is collected are all products of a wider social framework which is specific to each society and shapes the opportunities of individuals who live therein. In 
the contemporary digital age, the online community exists, which offers a growing and multiple learningbased opportunities.

Experiential learning, as defined by Kolb (1984), includes all learning experience are not acquired in any formal educational environment. Instead, it involves the practice of reflection concerning commonplace practices in personal and professional life. Thus, Experiential learning constitutes 'making meaning' as derived from actual-life experiences, which necessarily broadens to scope outside both the workplace and formal learning scenarios. Experiential learning could be maximized even in the case 'unintended, unstructured, and opportunistic' (Yardley et al., 2012, p.163).

Social learning theory puts great emphasis on firmly upon so-called communities of practice. This approach is predicated upon the assumption that both learning and thinking are primarily social activities which are framed in accordance with the tools presented in different learning circumstance (Taylor \& Hamdy, 2013).

\section{CONSTRUCTIVISM AS A THEORETICAL BASIS FOR LIFELONG LEARNING IN THE ONLINE LEARNING ENVIRONMENT}

While there exists a spectrum of learning theories which can be explored in connection with adult learning, the author state that the most relevant theory is constructivism. This approach contends that knowledge construction by the learner can be formed from both their existing knowledge and their social interaction process with their surrounding environment. As with other learning theories of adult learning, constructivism and Adult Learning Theory concur in terms of the tenets and techniques and their methodology regarding the teaching of adults. Hence, in both approaches, authenticity and relevant learning are crucial components. The adoption of a constructivist approach requires the provision of learning experiences which learners regard as pertinent to either their working or non-working lives. Hence, this philosophical stance recognizes that adult learners are motivated by a combination of social, emotional, or occupational needs (Annette, 2010). Moreover, as has been stated by Lambert (2002), constructivist leadership is grounded in the identical principles which inform constructivist learning. Specifically, both adults and children acquire knowledge and skills through a process of "meaning and knowledge construction, inquiry, participation, and reflection" (Lambert, 2002, p.35).

According to Piji Zieber (2009), since adult already possesses substantial knowledge and experience, construction of new understanding and knowledge must be built on this existing body of experience and knowledge. Thus, constructivist learning is closely reflectors real-life problem-solving practices, and constructivist principles can be regarded as being in accord with the general principles of adult education. Both Adult Learning Theory and constructivism have considerable relevance for the present and predicted social media-based communities, communications, and conceptual exchanges.

Billett (1996) emphasizes the value of the workplace as a stimulating environment for learning since it has obvious associations with genuine goal-directed action, provides access to relevant guidance from both observable experts and colleagues in the appropriate context, and involves routine problem-solving which facilitates indexing. Moreover, the workplace setting also acts as a prominent source of implicit reinforcement.

Research into workplace-based learning has proven that what occurs in such scenarios is essentially constructivist, situated learning, often via the process of cognitive apprenticeship. Billett's $(1993,1994)$ own research conducted concerned workers in the coal industry and other allied industries. The conclusions reached included the observation that in the informal learning environment of the workplace, active learning is a consequence of the combination of learner participation in authentic activities as guided by acknowledged experts and their interaction with other workers. While each learners have their own construction of understanding, which was unique to them, it was nevertheless was moulded by the culture of their workplace. Amongst these community workers, the instruction was esteemed solely for its potential to provide knowledge that they were unlikely to acquire indirectly, otherwise referred to as opaque knowledge.

Nevertheless, it was the quality of the instruction, which was considered the most essential component in their experience. Specifically, workers were unequivocal that their learning experiences must assist their comprehension of the reasons underlying working practices and that this information is presented in a manner which could not be construed as patronizing or demeaning (Billett, 1994). Hart-Landesberg, 
Braunger, and Reder's (1992) study investigated the way hospital employees "learn the ropes", reflecting upon the processes through which these workers simultaneously learn and do. This study concludes that workers reflect upon their actions in order to interpret and reevaluate the knowledge they have obtained.

Action is critical to the creation of knowledge since it is through participation in regular work activities that learners are compelled to access higher-order procedural and propositional knowledge. The reiterative experience completes their index of knowledge, and active preoccupation with regular problem-solving underpins their learning. From a constructivist perspective, reinforcement indicates the inner gratification arising from making a wide sense of new stimuli or the adapting of new data to previously established frameworks of knowledge. This diverges significantly from the behavioural stance wherein reinforcement appears to be provided from external sources (Billett, 1994).

When a constructivist paradigm is adopted in the preparation and design of occupational training in the workplace, several features emerge. Workers and managers begin to appreciate that they have diverse and frequently opposed viewpoints about precisely what training is required. This occurs as a result of both parties acknowledging that they have constructed their perceptions of the organization independently. Moreover, an appreciation can, therefore, evolve wherein it is accepted that neither viewpoint is necessarily wrong (Annette, 2010).

According to Annette (2010), constructivism requires that the opinions of each group regarding training are given due consideration. For this to occur, dialogue and discussion are required to an enhanced comprehension of others' understandings of reality can be derived. Consequently, meaningful training programs can emerge to fulfil the necessary needs of the workers.

When job-related training is designed in accordance with a constructivist perspective, it could be fully compatible with both the managers' and the workers' constructions of reality. Taking the Master of Educational Technology "MET" Courses as an example, which are specifically designed courses for graduates to acquire a deep understanding of learning supported by advanced technologies in various organizational settings (The University of British Columbia, 2019). These courses are characterized by their construction around a discussion-based format. Wherein, the role of instructors is to supervise discussions on the forums, but not to interfere in any explicit way. Hence, participants are free to communicate and openly respond to each other, thereby promoting cooperation and enabling learners to generate subject knowledge by paying attention to the opinions expressed by other participants and integrating what they understand within their existing knowledge. This process is rendered authentic by the inclusion as illustrative instances from learners' own examples, experiences, and contexts related to their work (Annette, 2010).

It is vital that any instructional approach supporting lifelong learning acknowledges that each adult learner possesses a learning style which is both characteristics and unique to them (Holmes, 2002). Since all adult learners arrive in the learning environment equipped with a wealth of knowledge and real-life experience, the adult learning environment must constructively utilize this to create an instructional activity that is both worthwhile and effective for the learner.

While constructivist learning theory actively supports the learning characteristics of adult learners, its theoretical foundations do not explicitly advocate any precise learning approach. The strength of the constructivist approach lies in their support of lifelong learning through recognizing the distinguished traits of adult learners (Fosnot, 2005). Constructivism puts stresses on the role of social interaction, reflection, and the incorporation of prior experience in the meaning-making process by the learner (Steffe \& Gale, 1995). One underlying assumption in constructivist thought is that real-world problem-solving can be meaningfully practised in a collaborative work setting as an instrument to link existing knowledge and experience with current learning while concurrently facilitating the social construction of knowledge. In this specific way, the primary tenets of constructivism promote the learning styles and characteristics of adult learners, while it does not present any identifiable implementation strategy.

One key element of a learning environment which has been created following socio-constructivist principles is it's the encouragement of collaboration among learners and practitioners in a communal framework (Szeyeng \& Raja, 2010). Furthermore, since constructivist theory advocates self-directed learning, responsibility is relocated "from teacher-directed courses to a negotiated curriculum" (Gunduz \& Hursen, 2015). The consequence of this conceptual shift that learners are both empowered in the delineation of their own 
learning prerequisites and provided with an appropriate opportunity in which to satisfy these specific needs through adopting effective strategies.

In such an environment, there is an expectation that learners will be proactive in the discussion, reflection, adaptation, evaluation, and engaging within the learning community through social interaction (Sze-yeng $\&$ Raja, 2010). Their self-directed conversation with both themselves and their community creates an active experience to acquire meaningful learning. The encouragement and direction supplied by both experts and most professional peers foster learner competence and aptitude for learning, as per Vygotsky's (1978) concept of the 'Zone of Proximal Development'.

Perhaps the most significant feature of the lifelong learner is the capacity for self-direction. In other words, the learner's independence in managing the entire learning process. This requires perspicacity regarding one's predisposition for self-direction and active decision-making, in addition to the ability to own responsibility for the lifelong learning process. From an instructional perspective, this necessitates that learners demonstrate initiative, irrespective of the existence of any formal guidance, and make choices concerning their own learning. Pedagogical approaches which incorporate problem-based, case-based, and team-based learning are proven to enhance self-directed learning skills (Blumberg, 2000).

Using scaffolds in a technology-integrated social constructivist learning environment is assimilated within any given self-directed instructional scheme. By participating in the use of relevant web tools, the students can refine existing skills concerning cooperation, negotiation, interaction, and reflection, and in this way promote their own lifelong learning characteristics (Lamon, Reeve \& Scardamalia, 2001). Amongst the associated visual tools itemized by Hyerle (1996) are brainstorming webs, concept mapping, thinking process maps, multimedia, and the World Wide Web, which support knowledge construction.

Web-based platforms such as Wikispace, Moodle, Google docs, and Facebook all serve as sophisticated tools to actualize self-directed learning. These technologies act as primary learning spaces for the promotion of initiative and autonomy in the creation of instructional design knowledge and skills. Hence, for instance, self-driven learning followed by guidance and comments from peers and instructors becomes navigable within a shared learning contract hosted by Google Docs (Sze-yeng \& Raja, 2010).

\section{LIFELONG LEARNING}

Lifelong learning is extensively known as the continuing process of updating knowledge, competencies, and skills of individuals in the ever-changing world, used for improving their social life (Koper \& Tattersall, 2004).

When conceived as a means of continually acquiring new expertise and experience new activities, lifelong learning can be considered to positively impact individual lives through the enhancement of qualities such as the ability to absorb and retain information, creativity, the capacity to the adaptation to new conditions, and learn from past mistakes. Yet, irrespective of its clear advantages in terms of personal growth, lifelong learning also offers a positive route for professional development, guaranteeing autonomous learners have enhanced skills, which will permit them to compete more effectively in the marketplace. Such benefits are invaluable in a contemporary society, which places increasing emphasis on technologies which enable more rapid means of information acquisition (Bizon \& Istrate, 2017) ever.

When regarded in a wider, more abstract manner, lifelong learning encompasses all the varieties of activities and experiences which allow individuals to acquire wisdom and edification and to thereby become more prominent members of the community. As an active and effective philosophical approach to the pursuit of knowledge acquisition, lifelong learning has a demonstrable capacity for achieving and accelerating a social transformation. As an educational movement, it promotes the message that it is never too early nor too late to learn. Furthermore, lifelong learning can create systematic changes in social attitudes and values, through upholding the concept remaining open to new ideas, philosophies, skills, behaviours, and attitudes (Kumar, 2012).

Such a conclusion confirms Lamb's work (2005) that refers to lifelong learning as a mechanism through which novel skills and knowledge are acquired, and it can have an influence on the formulation of new opinions. Such a potentially paradigm-shifting process naturally extends well beyond the scope of any mere 
classroom-based activity or reading a book related to self-improvement. It requires the making wise decision concerning how an individual prefers to live their life and the resolving of any obstacles which hinder a chosen course of action.

\section{Different Aspects of Lifelong Learning}

According to the working report of the Commission of the European Communities (2000) Education does not simply refer to only lifelong learning, but in that official paper, all forms of education were described as follows:

- Formal education occurs within recognized educational institutions and typically results in the awarding of qualifications such as official diplomas and certificates.

- The forms of non-formal education co-exist with the formal system and frequently do not result in any formal qualification. Such learning may occur at the instigation of organizations and take place in the workplace environment, such as trade unions, youth organizations, and political groups. This form of education serves as an adjunct to the formal system of education and can encompass fields as diverse a sport, music, or even preparation for examinations.

- Informal learning regards as an entirely natural aspect of ordinary life since unlike formal education, it can occur in such an unconscious level that the recipients of this learning need no even officially acknowledge that they have acquired new skills or knowledge.

Lifelong learning inevitably denotes both informal and non-formal education. The non-formal learning concept stands apart from schools, colleges, training centres, and other recognized institutions for learning. Typically, the outcomes of non-formal learning rarely carry much value in the market sector. Hence, nonformal education is not regarded as real learning and generally somewhat undervalued (Pureta, 2015).

\section{The Characteristics of the Lifelong Learner}

According to Mackeracher (2004), the determining characteristics which define the successful lifelong learner are a capacity for reflective learning and the possession of critical thinking skills. These abilities enable the learner to gain self-reliance through learning how to learn. Consequently, these lead to increasing personal independence and the ability to regulate the learning process actively. In a similar vein, Dunlap (1997) observes that in order to prepare higher education students for the role of lifelong learners, it is essential that the core skills of self-direction, metacognitive awareness, and natural tendency toward learning to be enhanced.

However, it should not be assumed that the necessary fundamentals for success in lifelong learning, such as personal and interpersonal skills, are intrinsic to most workers. Lifelong learning requires self-reliance, motivations, reflection, and interpersonal skills. Above all, learners must adopt a proactive role in their education with particular reference to the knowledge construction as well as sharing of both knowledge and experience (Kerka \& Eric Clearinghouse on Adult, 1996).

While the primary skill required for lifelong learning is the ability to efficaciously read and absorb materials, which include exposure to new knowledge. Besides, being possessed of a capacity to interact socially is imperative since knowledge accrued from reading must subsequently be filtered via a process of participation in pertinent projects, peer sharing, and mentorship (Holmes, 2002). Furthermore, the learner must refine the requisite reflective skills in order to smoothly gain a more profound vision and understanding of the newlyacquired knowledge and experience. As a rule, neither the personal nor the interpersonal skills necessary for successful lifelong learning are provided by any contemporary epistemological approaches (Gorard \& Selwyn, 2005).

Stauble (2005) argues that lifelong learning equates to a cyclical process wherein it is possible to identify four key pillars, each with e-portfolios, to support them. The first of these pillars concerns Self-awareness emphasizes the existing knowledge, experience, and attitudes of a learner in respect of the education process. Thus, a portfolio comprises a valuable tool whereby a learner can be made aware of their personal progress. The second pillar can be described as self-management or planning for learning objectives that are established 
and a strategy for achieving them enacted. At this stage, a portfolio has the advantage of acting as a map for future learning. The third pillar is Meta-learning or the process through which learners comprehend how they learn. It denotes how a learner acquires an awareness of diverse approaches to knowledge acquisition, such as deep versus surface learning, and Rote versus meaningful learning. The variety of different learning styles is also encompassed in this particular pillar. The fourth and final pillar is self-monitoring, or the capacity to evaluate learning, wherein a learner systematically evaluates all elements of their own learning experience and performance. The self-monitoring process equates to the acceptance of responsibility for meaning-construction and correlates with the capacity to engage in reflective and critical thinking.

Despite the apparent significance of these pillars to any successful teaching and learning process, lifelong learning can be chiefly characterized as a reflective cycle. Thus, the portfolio exemplifies the most efficacious context for this refection (Stäuble, 2005).

\section{METHODOLOGY}

The methodological stance adopted in the current paper centres on a literature review of pertinent theoretical knowledge in the field of lifelong learning. There are three principal areas which this paper seeks to explore. The first of these comprises an exploration of what lifelong learning is and why we need for. Secondly, this paper examines different approaches to the development of both the personal learning environment (PLE) and the personal learning network (PLN) within the overall context of lifelong learning. Finally, this paper also considers the way in which a constructivist approach enhances our understanding both of the embracing of technology in the lifelong learning process and of the adoption of apposite lifelong learning strategies. The inclusion in this paper of descriptions of multiple search engines, blogs, and social networking sites is intended to be illustrative of the use of such platforms for learning and career development in addition to incorporates statistical information related to adult use of such sites.

\section{Technology as a $21^{\text {st }}$ Century Tool for Learning}

In contemporary society, technology has become completely enmeshed with every area of daily life. Countless individuals regularly log on to the Internet to conduct different kinds of tasks, including the checking of e-mails, online banking, job hunting, or simply to surf the net. Technology is now so integral to our commonplace existence that it has become almost impossible to conceive of performing a particular function without access to the Internet or a computer. Moreover, many families have now invested in computer connections and wireless networks in their homes. Internet access is deemed vital necessities as food consumption (Atzori, Lera \& Morabito, 2010). Social networking site usage has increased exponentially amongst all age groups, with $89 \%$ of young American adults being regular Internet users, while over twothirds of American Internet users aged 30 to 64 use social networking sites (Pew Research Center, 2014). Even among American adult Internet users over the age of over 65 , some $46 \%$ regularly engage in social networking (Pew Research Center, 2014). Statistically, Facebook, which newly celebrated the fifteenth years of anniversary, is maintaining its position as one of the most popular social media platforms in the United States. An estimated 69\% of American adults claim to have used Facebook at some point, despite the fact that a 2018 Center survey has reported a marked decline in Facebook usage amongst the younger population. Teenagers, in particular, are using Facebook with less frequency. However, age-related disparities in Facebook usage are less pronounced amongst users. Facebook use is equally popular across all age groups. In particular, $68 \%$ of fifty to sixty-four-year-olds and almost $50 \%$ of the over sixty-fives report using this platform. The only other social platform, which is equivalent and reaches the number of Facebook users, is YouTube, which boasts an adult usage of 73\% (Pew Research Center, 2019).

According to psychologists such as Albert Bandura, learning should be regarded as a social activity. Bandura theorizes that learning occurs through a process of modeling in respect of behaviors demonstrated by others. Likewise, Lev Vygotsky postulates that we learn through the process of social interaction (Taylor \& Hamdy, 2013; Yardley et al., 2012). While certain social interactions are collaborative, others are competitive. Moreover, some interactions occur among peer groups, whereas others are hierarchical in nature. In addition, interactions can transpire both in real-time and through turn-taking. There is a growing trend for social 
interaction among people from a more geographical dispersed distance, whereby technology allows it to show between individuals who are not connected through any means other than a shared field of interest related to their learning. This technological development has been greatly assisted by the advent of social networking platforms (Terry \& Yolanda, 2015).

Current social technologies authorize the connecting of users with others in ways that were formerly unthinkable. Furthermore, phenomena of technology-based social media such as blogs, discussion forums, social networking sites, image sharing services, and video sharing services, enable individuals not only to connect with others but also to share learning resources (Kimmons, 2018).

Consequently, technology tools have a distinct application in the arena of lifelong learning, which can be into two principal categories: personal learning environments (PLE) and professional learning networks (PLN). The current paper examines both the different approaches to lifelong learning and the tools available to support it.

\section{Personal Learning Environments}

Those processes which are referred to as Personal Learning Environments (PLEs) enable learners to assume responsibility for and control over their own learning. The three core ways in which this occurs are the establishing of personal learning goals, the regulating of the content and process of learning, and the creating of communication between those involved in the learning experience as it evolves (Municipality of Halmstad $\&$ the European Commission).

With the advent of technological advances, there is an increasing preference for personal learning environments (PLEs) among leaners. While a PLE is essentially a collection of go-to tools that learners can employ to assist them in their learning tasks, the focus is increasingly placed upon the analysis and evaluation of information. This enables learners to relate to concepts in a variety of ways, which are now feasible only as a result of access to certain widely-available technologies (Jenkins, 2017).

Hence, a learner, while working on a research assignment, can visit multiple websites using a bookmarking tool such as Diigo wherein tags are employed to enable the learner to easily retrieve specific information. In addition, the audio recorder on a smartphone or tablet can efficiently log transient ideas throughout the day. Alternatively, a learner might utilize OneNote Learning Tools to ensure correct grammar usage and transitions between the paragraphs in an assignment (Jenkins, 2017).

Technology can also be used to enable learners to locate and join discussion groups pertaining to their specific fields of learning, while content sharing platforms, such as YouTube and Vimeo, allow anybody to view learning content or to post their own content. These and countless other tools exemplify a personal learning environment in which current technology assists active lifelong learning (Bizon \& Istrate, 2017).

\section{Professional Learning Networks}

Professional Learning Networks (PLNs) comprise groups who collaboratively participate in learning alongside those who are external to their commonplace community of practice, the aim therein being to enhance teaching and learning in their own system (Brown \& Poortman, 2018). According to Faisa (2015), a PLN is a group of connected individuals or professionals who share and exchange ideas and knowledge to increase their mutual appreciation of any given field of their interest. PLNs recognize that experience has the innate potential to be a better teacher than teachers themselves. Thus, even a PLN is most effectively understood from within.

The recognition that networking functions most effectively at the level of teachers has resulted in increasing attention paid by policymakers and educationalists to PLNs as a means to improve education within formal settings (Armstrong, 2015).

Figure 1 presents a graphical conceptualization of PLNs wherein each black dot or white star represents an individual stakeholder, such as a teacher or an academic researcher. The arrows, meanwhile, represent connections and so flows of information or other forms of social capital that occur between professionals. As can be seen from the illustration, there are two types of grouping. The first, as demarcated by dotted circles, 
denotes everyday communities of practice, such as individual schools or university departments (Wenger, 1998), whereas the second type of grouping, as signified by the mass of black dots in the diagram's center, constitutes a PLN. Figure 1 illustrates how members of PLN, as represented by white stars, equate those individuals possessing connections which extend beyond the dotted circles of ordinary communities of practice and into the network of individuals placed at the diagram's center. Thus, PLNs can be composed of separate individuals from a range of communities of practice (Brown, 2019).

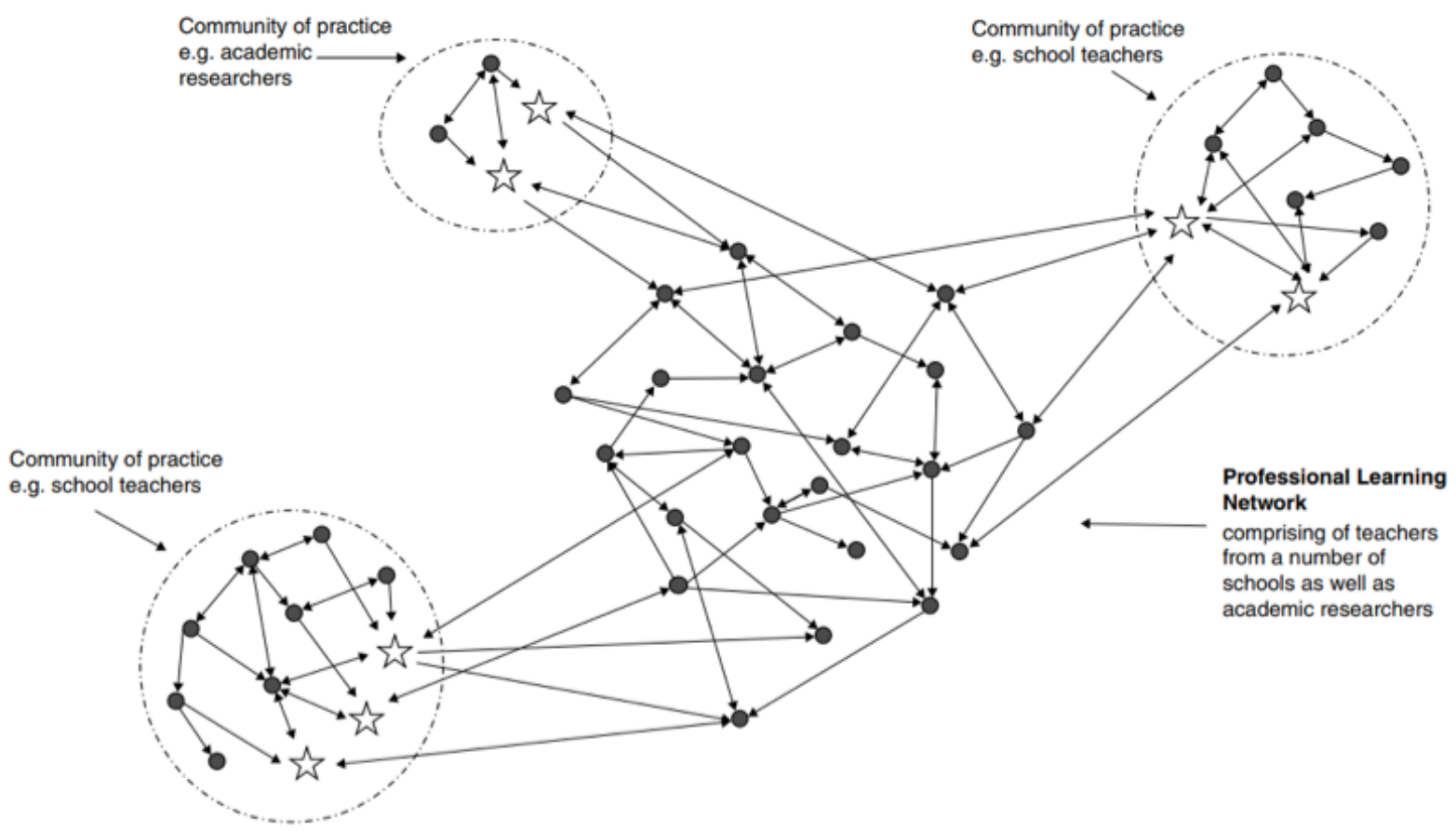

Figure 1. A graphical Depiction of PLNs. (Brown, 2019, p.5)

Despite the increased professional devoted to PLNs, the paucity of research into PLNs and their consequences remains pronounced. Most research into online teacher learning emphasizes the learning experiences of the teachers from within a single network or community of practice or is connected to a specific online platform, such as Twitter (Carpenter \& Krutka, 2014; Gesthuizen, 2012; Hur \& Brush, 2009; Kelly \& Antonio, 2016; Trust, 2015; Visser, Evering, \& Barrett, 2014). As with PLNs, teachers participate in these online spaces in order to identify and exchange professional expertise (Carpenter \& Krutka, 2015; Trust, 2015; Duncan-Howell, 2010; Forte, Humphreys \& Park, 2012), or to establish cooperative relationships with like-minded professionals (Carpenter \& Krutka, 2014, Carpenter \& Krutka, 2015; Hur \& Brush, 2009; Visser et al., 2014). Some studies were examined on how online platforms also possess the potential to shape teacher identities (Barab, Kling \& Gray, 2004; Luehmann \& Tinelli, 2008).

Ronfeldt, Farmer, McQueen \& Grissom (2015) report a beneficial impact on student performance arising from scenarios where teachers within a community of practice, participate in active collaboration with their colleagues. Nevertheless, research into the collaboration between teachers from diverse communities of practice is less well-defined. It is possible, perhaps, that such collaborative activity could result in a valuable cross-pollination of ideas and practices, as per Forte et al. (2012).

Research conducted by Trust, Krutka \& Carpenter (2016) observes that teachers who participate in PLNs are enthused by their engagement with others and the potential this offers to satisfy their diverse, holistic needs. Furthermore, all research subjects appeared to acknowledge the social, intellectual, emotional, and identity-related advantages of PLN participation.

Similarly, lifelong learning has also been deemed to enhance career satisfaction, as is confirmed by Afonso et al.'s (2017) research into psychiatrists, which indicates that motivation to remain up-to-date with current 
developments in one's field has a strong correlation with career satisfaction. When a given professional field is characterized by fast-paced change, social media platforms might enable practitioners to stay updated and, therefore, simultaneously promote a sense of fulfilment.

The current range of tools can be adopted to create a professional and Personal Learning Environment. Some examples include search engine alerts, personal knowledge managers, RSS feed aggregators, and video sharing services; each of examples tools are explored in a bit more detail.

\section{Video-Sharing Services}

Both lectures and hands-on teaching have comprised the educational norm for centuries. Technology now permits video-based or multi-media interactive tools to supplement the standard curriculum, offering an additional format through which education in person can be strengthened (Terry \& Yolanda, 2015). Multiple hosting services are currently available, such Web sites and blogs, which permit the uploading of video content and courseware. These services store podcasts and assign them URLs so that other users can access them. The most popular hosting site is YouTube, which is a free multipurpose site. Videos uploaded onto YouTube are both searchable and shareable, enabling the site to be used by both professional and non-specialist audiences. Whilst a member is a prerequisite of the ability to upload videos or to comment on those created by other members, even nonmembers are able to access videos for free watching (Gilton, 2016). Thus, YouTube offers immense potential as a tool for lifelong learning since not only does the site's commenting facility enables users to review and potentially revise the content of the video, but it also permits the sharing of YouTube video content on other online platforms, such as blogs and websites (Topps et al., 2013). Videos can be made available for review or revision by learners following live performance or can simply be employed as sources of advice or suggestions (Fischer et al., 2013). Large universities, including MIT, Harvard, and Stanford, have launched their own YouTube channels through which lecturers can upload educational videos for free worldwide viewing. Hence, Social Media considers an ideal platform for lifelong learning, a modern concept that helps individuals keep their minds sharp and healthy by arousing their curiosity and providing new experiences throughout the entire life (Bizon \& Istrate, 2017).

Goleman (1998) emphasizes that emotional intelligence can be closely tied to videos. Gardner's conceptualization of intrapersonal and interpersonal intelligence is alike to Goleman's emotional intelligence. Thus, personal intelligence can be deemed to comprise self-direction, self-reflection, self-motivation, planning, impulse control, independent study, and metacognition, whereas interpersonal intelligence emphasizes activities such as relating, empathizing, cooperating, leading, teaching, connecting with others, resolving conflicts, and social activities. The music incorporated within videos can elicit various emotional reactions, including liking or disliking, and generating excitement or arousal (North \& Hargreaves, 1997; Robazza, Macaluso \& D'Urso, 1994). Thus, video is a valuable means of establishing a more profound level of communication with learners through the creation of an emotional bond. Similarly, Haridakis \& Hanson (2009) have observed that YouTube established direct connections to users' and interpersonal activities since they can share videos with others within their social surroundings, indicating a correlation between offline social activities and interpersonal interaction may affect the YouTube use for a social purpose.

Several academic institutions are already adopting YouTube as a vehicle for the dissemination of knowledge, such as course modules. Thus, Jaffar (2012) observes that $98 \%$ of medical students used YouTube videos as an online information resource, with $86 \%$ reporting that they have confidence in the platform's capacity to assist their independent learning.

Likewise, Bizon \& Istrate's (2017) review of online lifelong learning platforms Based on Social Networks reveals that over $65 \%$ of users in their study regard video recordings as an ideal learning medium, following by audio recording and written materials. Roodt \& Peier's (2013) research confirms the value of YouTube use in class for illustrative purposes in the classroom context. That particular study indicates that $71 \%$ of students believe YouTube video usage raised their attention spans, while over $50 \%$ of respondents agreed that YouTube usage was generally beneficial. Overall, $65 \%$ of respondents would prefer such videos to be incorporated into their future learning. 


\section{Search Engine Alerts}

Search engine alerts, such as Google Alerts, are entirely free online software tools which enable users to track selected keywords and expressions in connection with a content change detection and notification service. This search facility is supported by Google, which sends emails to users when new results are indicated. These results include web pages such as Wikipedia, blogs, and newspaper articles (Donchev, 2017). Thus, services like Google Alerts are provided by search engine companies that notify registered users when new relevant content becomes available on the web. In this way, for example, a social studies teacher can be sure to receive any news stories dealing with discrimination if they create a Google Alerts search criteria with the word "discrimination" (Kimmons, 2018).

In addition, there is increasing reliance placed upon the results of internet search engines, particularly when they have arrived by Google search motor. In 2003, Graham \& Metaxas's (2003) research into online users concluded that participants trust the information and often adopted an attitude of "Of course it's true, I saw it on the internet", indicating that users frequently regard Google as a source rather than a mere intermediary between themselves and multiple resources. These conclusions have been confirmed by other studies, such as the research conducted by (Lewandowski, Kerkmann, Rummele \& Sunkler, 2017).

Over 4.5 billion individuals were regular Internet users as of 2019 (Internet World Stats, 2019), with 90\% of adults in the US defining themselves thus in the same year (Clement, 2019). The search for information is acknowledged as one of the primary purposes of using the Internet. In particular, search engines play a primary role in this respect with Google, Yahoo, and Bing being reportedly used by $80 \%$ of online users. However, although each search engine employs a slightly different way of ranking content, all these search motor have in common the tendency to produce more results than any individual would be willing to read. Thus, most users focus on the top-ranked results (Allam, Schulz \& Nakamoto, 2014).

Purcell, Brenner \& Raine's (2012) study of U.S. internet users discovered that $91 \%$ of search engine users reported finding appropriate information via search engines. The $73 \%$ of them considered most or all the information thus found is accurate and reliable, and that $66 \%$ regarded search engines as fair and impartial sources of information (Pew Research Center, 2012). These findings suggest that there is a robust and significant correlation between user confidence in search engines and understanding of search engines as purely algorithmic systems for which reliability and bias issues are irrelevant.

There have been several studies which indicate that problems accrue as a result of variations in the quality of information obtained via search engines. Coupled with the aforementioned, there are concerns over search difficulties, information overload, poor organization, inadequate regulation, inaccuracy, and lack of quality in search engine results. Hence, some Internet users may have a poorly developed ability of judgment the quality of search engine findings. This applies, in particular, to users with more limited literacy skills. Whilst such concerns clearly pre-date the Internet, the impact has perhaps been exacerbated by the breadth of information available online. Besides, there is a perceived tendency for the information retrieved from search engine results to be accorded as an authoritative source. Once more, this misperception of information quality is not a new issue. Finally, it is entirely possible that users can regard the ranking of results in the search engines as indicative of the quality of information, rather than merely pertaining to other factors. Thus, the search engine can be mistakenly seen by the users as it is providing the most reliable or informative websites and content (Allam, Schulz \& Nakamoto, 2014).

\section{Social Networking Sites}

Technology-based social media have an active contribution to increasing access of people from various ranges of age to learning and probably passed socioeconomic levels throughout the world. As Merriam \& Caffarella (1999) observe, the social media age has contributed to the expansion of an environment in which individuals can all, irrespective of their personal demographic or socioeconomic status, can both access learning online and connect across vast geographical distances. Distance learning is a key component of the relationship between social media and lifelong learning. Through facilities such as networking and extensive participation before and after live sessions, social media can expand learning and relationships into a shared space as serve to promote professional growth (Kind et al., 2013). The interactive nature of social media is critical since it facilitates both 
the synchronous nature of information dissemination media and its asynchronous character as to manifest in conversations, chat forums and comment facilities. The interactivity allows learners to exchange opinions, ideas, and questions, and goals with actual or virtual peers and mentors, thereby establishing themselves as active partners in the learning process (Terry \& Yolanda, 2015).

Social networking sites, such as Facebook, Twitter, and Pinterest, are social spaces in which individuals people engage with friends and family. However, they can also perform an important professional function. Thus, strictly professional social networking sites, such as LinkedIn, allow users to manifest a professional online presence, which is of considerable value in the job-seeking process. Similarly, by creating a Twitter or Pinterest account and follow the posts of other professionals in a specific sphere of interest, users can stay remain up-to-date with relevant developments. Creating a profile and sharing professional expertise on such sites also allows users to share their knowledge in a manner which serves to assist others (Kimmons, 2018).

Since 2003 social networks achieved mainstream status achieved incredible audience figures. This explosive growth in audience number is exemplified by Facebook, in which 200 million worldwide users in April 2009 had raised to 400 million users by March the following year. By November 2010, Facebook's estimated audience exceeded 547 million users. With only $26 \%$ of the users residing in the United States, Facebook is a global phenomenon. Twitter usage demonstrates a less dramatic trajectory, rising from 19 million users in March 2009 to 75 million in March 2010, of which 44\% reside in the United States (Perez, 2011). The online survey was done by Clement (2019) indicates that as of the second quarter of 2019, global Facebook usage had reached 2.41 billion users, rendering this platform the unequivocal leader amongst social networking sites. In the US alone, there were a recorded 190 million Facebook users by July 2019. The last figures regard to international twitter usage demonstrate 330 million regularly active Twitter users as of the second quarter of 2019.

According to Redecker, Ala-Mutka \& Punie's (2010) survey on the Impact of Social Media on Learning in Europe, The European Commission Joint Research Centre contends that there is a growing tendency for the internet to be accessed for educational content. This is evidenced in Eurostat data, which reveals that in 2009 an average $31 \%$ of the EU27 population aged 16 to 74 already used the Internet to obtain educational content, up $8 \%$ from the figures for 2007 . Moreover, the geographical variation was not excessive, ranging between $20 \%$ and $50 \%$ in most European countries. Since portable devices connected to the internet are increasingly commonplace, these are also being employed as a gateway to learning without being physically linked to any specific time zone or location.

Bizon \& Istrate (2017) review of lifelong learning online learning platforms concludes that creating an online community has multiple benefits since over $45 \%$ of the respondents in the study claimed they would be happy to employ collaboration tools which enabled course participants and trainers to connect and share ideas.

\section{Blogs}

A weblog, usually referred to as a blog, is an online log entry through which writers regularly follow the routine to update content. Readers can make a constructive or critical comment on the post to which authors may choose to respond, asynchronously. The overall result is a reciprocal relationship between writers and readers, manifest as a reading and responding process (Chisolm, 2016).

Hyperlinks to specific texts are frequently incorporated in blogs, thereby permitting readers to instantaneously access the original information referenced in the blog post. This renders possible a more profound exploration of topics touched upon in a blog. Blogging, which references peer-reviewed evidence, such as those connected with journal clubs, morning reports, or conferences, can ensure these references are available to the reader either before, during, or after a specific live session (Chisolm, 2016).

Terry \& Yolanda (2015) contend that blogs provide opportunities for lifelong learning through the following nine principals: (1) Links to additional references (2) The summarized perspective of authors regarding recent research or current events (3) Comments and questions supplied by readers which can result in content updates (4) Searchability in terms of content (5) Opportunities for learners and educators to work on identifying knowledge gap and fill it (6) The facility for subscribers and followers receive updates and 
links (7) Reminders to educators to learners regarding the need to complete scheduled assignments or to address queries (8) Open access and full availability of multiple settings, via various devices (9) The provision of platforms for reflections and personal improvement.

\section{RSS Feed Aggregators}

Really Simple Syndication (RSS) can radically change the way in which online information is consumed, not least in relation to the dynamic content. RSS-enabled websites create a stream of Markup Language (XML) data, which summarizes the site content of the site Areas as diverse as news headlines, stock market data, weather, discussion board postings, or community-specific announcements. Programs called aggregators periodically explore subscribed feeds for updates and then syndicate them directly to the users' desktops. RSS content can be filtered according to customized criteria, and content can be aggregated from across multiple feeds to suit the defined user requirements. RSS offers the benefit of time-efficiency since users no longer have to move through masses of potential online sources to locate relevant content (Lee, Miller \& Newnham, 2008).

The inherent complexity concerning the receipt and management of content on social media platforms has been effectively lessened thanks to technologies such as RSS (Really Simple Syndication). This tool has permitted users to address more relevant issues, including self-evaluation, critical reflection, and the delivery of feedback to other users (Lee, Miller \& Newnham, 2008).

West, Wright, Gabbitas \& Graham (2006) make observations regarding their own use of RSS in conjunction with blogs as a means of encouraging reflective writing and student dialogue throughout a pre-service instructional technology course for teachers. Strongly, Cold (2006) suggests that RSS can be used to enhance student research skills since it facilitates the amassing of multiple sources in one location through targeted searches. Thus, learners can both receive course materials and keep current with new research in their chosen field.

In the author's opinion, RSS and blog aggregates enable blogs with feeds to be organized into discrete interesting domains, both in professional and personal respects. With such a breadth and depth of data available online, such tools refine the information which users actually come to read and avoid significant time-wasting.

The evident absence of familiarity with RSS amongst professional practitioners is indicative of a general lack of knowledge pertaining to the potential benefits offered by this form of technology. Hence, the Pew Internet and American Life Project disclosed that a mere 9\% of online users were aware of the capabilities of RSS (Rainie, 2005). The figure for younger adult users was only marginally higher, revealing that just $12 \%$ of users aged between eighteen and twenty-nine had a working knowledge of the implications of RSS technology (Lee, Miller \& Newnham, 2008).

Significant advances in wireless technology have furthered the expansion of RSS technology. Consequently, as reported by Business Week Online (2006), the number of RSS feed had significantly expanded from a mere 307,000 in January 2004 to more than 13 million by August 2005. This figure is in excess of twenty times greater than the overall number of new feeds for the same period (Glotzbach, Mohler \& Radwan, 2009).

Feedly, which is arguably the most successful RSS reader on the global market, has demonstrated a substantial increase in terms of its user base for the period 2013 to 2015 (McDowell, 2015). Furthermore, in December 2017 , a Verge online survey highlighted that $80 \%$ of respondents were still using an RSS reader, with $68 \%$ of those questioned reporting their usage as "religious" (Robertson, 2017). RSS usage statistics for 2019 indicate that 28,962,567 live websites employ RSS (RSS Usage Statistics, 2019).

Glotzbach et al. (2007) conducted a study in which 240 students studying the Internet course at Purdue University were provided with a brief introduction to RSS at the commencement of the semester. It was ascertained that most participants possessed little or no prior knowledge of this subject, even though most were majoring in a computing-related field. Comparisons between the start and end-of-semester tests revealed that participants demonstrated increased knowledge of RSS. Despite this, the minimum weekly usage increased only slightly, indicating a hesitancy to adopt this technology. 
Jenssen, Desai \& Callahan (2014) conducted a study which revealed that while RSS reader use correlates with elevated familiarity with selected articles, there was no correlation with enhanced understanding. Participants reported satisfaction with the RSS reader due to the fact that it is simple to use, accessible, and assists in their reading activities.

\section{CONCLUSION}

Digital technologies such as computers, tablets, and mobile devices are omnipresent, and they provide the easy way with which connections between users indicate their great potential to support lifelong learning outside formal educational contexts (Fischer \& Konomi, 2007; Clough et al., 2008). Proponents of lifelong learning are able to access content that allows them to acquire knowledge on both a theoretical and a practical level with content directly related to their specialist interests. This is exemplified by Wikipedia.org, YouTube.com, Academia.edu, Blog, or Google; all of these online platforms provide access to knowledge which can quickly extend lifelong learning (Pureta, 2015).

Constructivist learning principles emphasize the role of social interaction in knowledge construction. Likewise, lifelong learning focuses on the communication of new ideas by speaking and listening to others. This invariably promotes innovation and collective development (European Commission, 2012). The relevance of technology in an interconnected global society is evident. Rapid internet developments are continually challenging the prevailing pedagogy, and it is evident both that technology provides lifelong learning opportunities for technology users and that constructivist learning approaches can comprise a valuable foundation for the use of technology in the lifelong learning process (Huang, 2002; Isaacs, 2013; Afendi \& Embi, 2010; Koohang, Riley \& Smith, 2009).

To conclude, the specific characteristics of adult learners are promoted by a constructivist approach to learning, and increasingly when technology is employed as a key learning tool. Fosnot (2005) argues that while constructivism does not inevitably decree a particular approach to learning, its central tenets are supportive of lifelong learning since they enable the principal characteristics of adult learning to be recognized.

Acknowledgments: Saif Mohammed appreciates the financial support of Tempus Public Foundation from the Hungarian Government through the Stipendium Hungaricum Scholarship, which had funded international students to pursue study in Hungary, and The Doctoral Schools of Educational Sciences Program, which always supports research program and gives the new idea in research view. Dr. Laszlo Kinyo was supported by the Janos Bolyai Research Scholarship of the Hungarian Academy of Sciences.

\section{BIODATA and CONTACT ADDRESSES of AUTHORS}

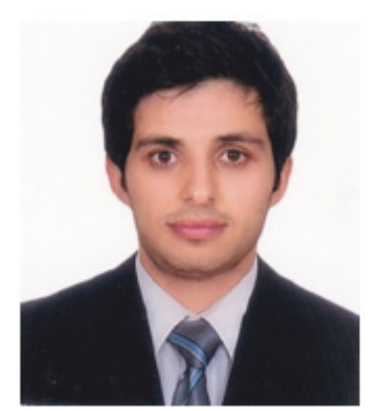

Saif MOHAMMED is a doctoral student at doctoral school of education, University of Szeged. Saif gained his Master degree in Educational science at February, 2012 in Bilkent University. His academic interest areas are learning theories, constructivism, educational technology, distance learning, e-learning, use of internet in education, citizenship and social science education. He has published 2 peer reviewed journal articles, and also participated in other national and international conferences. He served as educational specialist at general directorate of curriculum and printing in Ministry of Education-Iraq/ Erbil.

Saif MOHAMMED

Doctoral school of Education, Faculty of Humanities and Social Sciences

Address: University of Szeged, Doctoral school of Education, Petofi S. sgt. 30-34., 6722, Szeged, Hungary.

Phone: +36204359671

E-mail: mohammed.saif.husam@edpsy.u-szeged.hu 


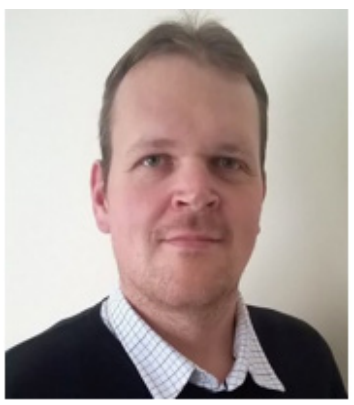

Dr. Laszlo KINYO is an Assistant Professor at the University of Szeged, Institute of Education, Hungary. Dr. Kinyo gained his Ph.D. in Educational Sciences in 2012. His main research interests are citizenship competence, social science education, and ICT in education. He also interested in computer-based assessment. $\mathrm{He}$ is publishing articles and participates on scientific conferences from 2005 in Hungary and abroad. He is author and co-authors more than 90 articles and conference materials on the field of educational scienes published in Hungary and international level. He holds university courses at the teacher training programs and at the Doctoral School of Education of the University of Szeged.

\section{Laszlo KINYO}

Institute of Education, Faculty of Humanities and Social Sciences

Address: University of Szeged Institute of Education, Petofi S. sgt. 30-34., 6722, Szeged, Hungary.

Phone: +36 305350959 ,

E-mail: kinyo@edpsy.u-szeged.hu

\section{REFERENCES}

Pew Research Center (2012, March 9). Search Engine Use 2012. Retrieved 07 23, 2019, from Pew Research Center Internet \& Technology: https:/www.pewinternet.org/2012/03/09/search-engineuse-2012-2/

Afendi, H., \& Embi A. M. (2010). Constructivism in the design of online learning tools. European Journal of Educational Studies 2(3), 237 -246.

Afonso, P., Ramos, M.R., Saraiva, S., Moreira, C.A., \& Figueira, M. I. (2017). Assessing the relation between career satisfaction in psychiatry with lifelong learning and scientific activity. Psychiatry Research, 210- 214.

Allam, A., Schulz, J. P., \& Nakamoto, K. (2014). The impact of search engine selection and sorting criteria on vaccination beliefs and attitudes: Two experiments manipulating google output. Journal of Medical Internet Research, 16(4):e100.

Annette. (2010, October 25). Can constructivist principals be applied to adult learning? Retrieved Sep 15, 2019, from http://constructivismetec522.pbworks.com/w/page/1845746/Adult\%20and\%20 Training\%20Applications

Armstrong, P. (2015). Effective partnerships and collaboration for school improvement: A review of the evidence. London: Department for Education.

Atzori, L., Lera, A., \& Morabito, G. (2010). The internet of things: A survey. Computer Networks, 54(15), 2787-805.

Barab, S., Kling, R., \& Gray, J. H. (2004). Designing for virtual communities in the service of learning. Cambridge, UK: Cambridge University Press.

Billett, S. (1993). What's in a Setting? Learning in the workplace. Australian Journal of Adult and Community Education, 1 (33), 4 -14.

Billett, S. (1994). Situated learning-A workplace experience. Australian Journal of Adult and Community Education, 2 (34), 112 -130.

Billett, S. (1996). Towards a model of workplace learning: The learning curriculum. Studies in Continuing Education, 1(18), 43-58.

Bizon, C., \& Istrate, A. (2017). Lifelong learning platforms based on social networks. Economy Informatics, $17(1), 14-24$.

Blumberg, P. (2000). Evaluating the evidence that problem-based learners are self-directed learners: A review of the literature. D. E. Hmelo (Ed.) Problem-based learning: A research perspective on learning interactions (pp. 199-226). New Jersey: Lawrence Erlbaum Associates Publishers. 
Brown, C., \& Poortman C. (2018). Introduction. C. B. Poortman (Ed). Networks for learning: effective collaboration for teacher, school and system improvement. London: Routledge.

Brown, C. (2019). Exploring the current context for Professional Learning Networks, the conditions for their success, and research needs moving forward. Emerald Open Research, 1(1), 1 - 19.

Burman, N.J., Boscardin, C.K., \& Van Schaik, S.M. (2014). Careerlong learning: Relationship between cognitive and metacognitive skills. Medical Teacher, 36, 715 - 723.

Carpenter, J. P., \& Krutka, D. G. (2014). How and why educators use Twitter: A survey of the field. Journal of Research on Technology in Education, 46(4), 414 - 434.

Carpenter, J. P., \& Krutka, D. G. (2015). Engagement through microblogging: Educator professional development via Twitter. Professional Development in Education, 41(4), 707- 728.

Chisolm, M. S. (2016). Social media in medicine. New York: Routledge.

Clement, J. (2019, August 9). Social media \& user-generated content. Retrieved Sep, 11, 2019, from Statista: https://www.statista.com/statistics/268136/top-15-countries-based-on-number-of-facebookusers/

Clement, J. (2019, June 18). U.S. internet usage penetration 2019, by age group. Retrieved Sep, 11, 2019, from statista: https://www.statista.com/statistics/266587/percentage-of-internet-users-by-agegroups-in-the-us/

Clough, G., Jones, A., McAndrew, P., Scanlon, E. (2008). Informal learning with PDAs and smartphones. Journal of Computer Assisted Learning 24,359-37.

Cold, S. (2006). Using Really Simple Syndication (RSS) to enhance student research. SIGITE Newsletter, 3(1), 6- 9 .

Commission of the European Communities (2000). A memorandum on lifelong learning. Retrieved 724 , 2019, from http://tvu.acs.si/dokumenti/LLLmemorandum_Oct2000.pdf

Darkenwald, G., \& Merriam, S. B. (1982). Adult education: Foundations of practice. New York: Harper \& Row.

Donchev, D. (2017, June 15). 12 Alternatives to Google Alerts for Tracking Mentions Across the Web. Retrieved 8 8, 2019, from Social Media Explorer: https://socialmediaexplorer.com/content-sections/toolsand-tips/12-strong-alternatives-google-alerts-track-mentions-across-web/

Duncan-Howell, J. (2010). Teachers making connections: Online communities as a source of professional learning. British Journal of Educational Technology, 41(2): 324-340.

Dunlap, J. C. (1997). Preparing students for lifelonglLearning: A review of Instructional Methodologies. Paper presented at the Association for Educational Communications and Technology Annual Meeting, Albuquerque, N.M. Retrieved January 1, 2019, from https://files.eric.ed.gov/fulltext/ED409835.pdf

European Commission. (2012). The European Higher Education Area in 2012: Bologna process. Retrieved August 12, 2019, from http://www.ehea.info/media.ehea.info/file/2012_Bucharest/79/5/ Bologna_Process_Implementation_Report_607795.pdf

Faisa, 1. S. (2015). Personal Learning Network: A powerful Tool for Professional Development. In Annu George, Savithry T.K., Vimal Kumar V., and Jasimudeen S. (Eds), Paradigm Shift in Libraries: A Festschrift to Rev. Fr. Jose Viruppel (pp. 59-69). Kottayam: Kerala Library Association, 1-13.

Fischer, G., \& Konomi, S. (2007). Innovative socio-technical environments in support of distributed intelligence and lifelong learning. Journal of Computer Assisted Learning, 23, 338 -350.

Fischer, J., Geurts, J., Valderrabano, V., \& Hugle, T. (2013). The educational quality of YouTube videos on knee arthrocentesis. Journal of Clinical Rheumatology, 19, 373 - 376.

Forte, A., Humphreys, M., \& Park, T. (2012). Grassroots professional development: How teachers use twitter. Proceedings from Sixth International AAAI Conference on Weblogs and Social Media. Dublin, Ireland.

Fosnot, C. T. (2005). Constructivism: Theory, perspectives, and practice. New York: Teachers College Press. 
Gesthuizen, R. J. (2012). Why build your own PLN? Proceedings from ACEC2012. Australian Computers in Education Conference. Perth, Australia.

Gilton, D. L. (2016). Creating and promoting lifelonglLearning in public libraries. New York: Rowman \& Littlefield.

Glotzbach, R.J., Mohler, J.L., \& Radwan, J.E. (2007). RSS as a course information delivery method. In Proceedings of the ACM SIGGRAPH 2007 educators program.

Goleman, D. (1998). Working with emotional intelligence. New York: Bantam Books.

Gorard, S,. \& Selwyn N. (2005). What makes a lifelong learner? Teachers College Record, 107(6), 1193- 1216.

Graham, L., \& Metaxas, P. T. (2003). Of course, it's true; I saw it on the internet! critical thinking in the internet era. Communications of the ACM, 46(5), (pp. 71-75).

Haridakis, P. \& Hanson, G. (2009). Social interaction and co-viewing with youtube: blending mass communication reception and social connection. Journal of Broadcasting \& Electronic Media, 53(2), 317- 335.

Hart-Landesberg, S. Braunger, J. and Reder, S. (1992). Learning the Ropes: The Social Construction of workbased Learning. Berkeley, CA: National Center for Research in Vocational Education.

Holmes, A. (2002). Lifelong learning. Oxford, U.K: Capstone Publishing.

Huang, H. M. (2002). Toward constructivism for adult learners in online learning environments. British Journal of Educational Technology, 33, 27 -37.

Hur, J. W., \& Brush, T. A. (2009). Teacher participation in online communities: Why do teachers want to participate in self-generated online communities of K-12 teachers? Journal of Research on Technology in Education, 41(3), 279-303.

Hyerle, D. (1996). Visual Tools for Constructing Knowledge. Alexandria, VA: Association for Supervision and Curriculum Development.

Internet World Stats. (2019, October 4). Internet Usage Statistics. Retrieved Sep, 10, 2019, from Internet World Stats, Usage and Population Statistics: https://www.internetworldstats.com/stats.htm

Isaacs, L. A. (2013). Social Constructivism and Collaborative Learning in Social Networks: The Case of an online Masters Programme in Adult Learning. Electronic Thesis and Dissertation Library, 1-95. Retrieved from http://etd.uwc.ac.za/xmlui/bitstream/handle/11394/5130/Isaacsla_med_ edu_2013.pdf?sequence $=1$

Jaffar, A. A. (2012). YouTube: An emerging tool in anatomy education. Anatomical Sciences Education, 5(3), 158- 164.

Jenkins, J. (2017, February 14). Personal Learning Environments. Retrieved 08 01, 2019, from ETSMAGAZINE Education Technology Solutions: https://educationtechnologysolutions. com/2017/02/personal-learning-environments/

Jenssen, P. B., Desai, R. B., \& Callahan, M. J. (2014). Randomized Controlled Trial of RSS Reader Use and Resident Familiarity With Primary Literature. Journal of Graduate Medical Education 6(2), 341- 344 .

Johnson, R. (2010). Supporting Life-Long Learning with Constructivist Web-based Instruction. Retrieved Sep, 20, 2019, from https://rjssqlservernotes.files.wordpress.com/2010/09/constructivism.pdf

Kelly, N., \& Antonio, A. (2016). Teacher peer support in social network sites. Teaching and Teacher Education, $56,138-149$.

Kerka, S. \& C. a. V. E. C. O. H. Eric Clearinghouse on Adult. (1996). Distance Learning, the Internet, and the World Wide Web. ERIC Digest: Columbus, OH.

Kimmons, R. (2018). Lifelong learning. Anne O.-L. \&. Kimmons (Eds.) The K-12 Educational Technology Handbook. EdTech Books. 
Kind, T., Patel, P.D., \& Lie, D. (2013). Opting into online professionalism. Paediatrics, 132(5), 792 - 795.

Kolb, D. (1984). Experiential learning. Englewood Cliffs, NJ: Prentice-Hall.

Koohang, A., Riley, L., \& Smith, T. (2009). E-learning and constructivism: From theory to application. Interdisciplinary Journal of E-Learning and Learning Objects, 5, 91 -109.

Koper, R., \& Tattersall, C. (2004). New directions for lifelong learning using network technologies. British Journal of Educational Technology, 35, 689-700.

Kumar, A. (2012). Philosophical background ofaAdult and lifelong learning. Retrieved Sep, 25, 2019, from UNESCO: http://aladin.uil.unesco.org/paldin/pdf/course01/unit_03.pdf

Lamb, A. (2005). Lifelong learning, Information inquiry for teachers. Retrieved July 15, 2019, from http:// eduscapes.com/infooriginal/life.html

Lambert, L. (2002). The constructivist leader. (2nd revised edition). New York, NY: Teachers College Press.

Lamon, M., Reeve, R., \& Scardamalia, M. (2001). Mapping the growth of deeply principled understandings in a knowledge-building community. Seattle, WA: Annual Meeting of the American Educational Research Association.

Lee, M. J.W., , M., Charlynn \& Newnham L. (2008). RSS and content syndication in higher education: Subscribing to a new model of teaching and learning. Educational Media International, 45, 311-322.

Lewandowski, D., Kerkmann, F., Rummele, S., \& Sunkler, S. (2017). An empirical investigation on search engine ad disclosure. Journal of the Association for Information Science and Technology, 1- 27.

Luehmann, A. L., \& Tinelli, L. (2008). Teacher professional identity development with social networking technologies: learning reform through blogging. Educational Media International, 45(4), 323-333.

Mackeracher, D. (2004). Making sense of adult learning. (Second Edition). Toronto: University of Toronto Press.

Laal, M., \& Salamati, P. (2012). Lifelong learning; why do we need it? Procedia - Social and Behavioral Sciences, 31, 2.

McDowell, G. (2015, March 25). Is RSS Dead? A Look At The Numbers. Retrieved October 12, 2019, from WEB CULTURE: https://www.makeuseof.com/tag/rss-dead-look-numbers/

Merriam, S.B., \& Caffarella, R.S. (1999). Learning in adulthood: A comprehensive guide. San Francisco, CA: Jossey-Bass.

Municipality of Halmstad \& The European Commission. (n.d.). Innovative Methods for award Procedures of ICT Learning in Europe. Retrieved Sep, 10, 2019, from: http://www.imaile.eu/about/ple-personallearning-environments/

North, A.C., \& Hargreaves, D. J. (1997). Liking, arousal potential, and the emotions expressed by music. Scandinavian Journal of Psychiatry, 38, 45- 53.

Gunduz N. \& Hursen C. (2015). Constructivism in teaching and learning; Content analysis evaluation. Procedia - Social and Behavioral Sciences, 191, 526 - 533.

Perez Latre, F. P. (2011). Social Networks, media and audiences: A literature review. Communication \& Society, 24(1), 63- 74 .

Pew Research Center. (2014). Pew Research Center Internet Project January Omnibus Survey. Retrieved Sep, 01, 2019, from https://www.pewinternet.org/fact-sheet/social-media/

Pew Research Center (2019, April 10). FACTANK News in The Numbers. Retrieved October 1, 2019, from pewresearch.org: https:/www.pewresearch.org/fact-tank/2019/04/10/share-of-u-s-adults-usingsocial-media-including-facebook-is-mostly-unchanged-since-2018/

Piji Zieber, E. (2009). Can constructivist principals be applied to adult learning? Retrieved Sep 22, 2019, from http://constructivismetec522.pbworks.com/w/page/1845746/Adult\%20and\%20Training\%20 Applications 
Purcell, K., Brenner, J., \& Raine, L. (2012). Search engine use 2012. Washington DC. Retrieved from http:// pewinternet.org/ / media/Files/Reports/2012/PIP_Search_Engine_Use_2012.pdf

Pureta, I. (2015). Lifelong learning process using digital technology. Interdisciplinary Management Research, $11,39-48$.

Rainie, L. (2005). Public awareness of internet terms. Retrieved Sep, 10, 2019, from Washington, DC: Pew Internet $\&$ American Life Project: http://www.pewinternet.org/pdfs/PIP_Data_Techterm_aware. pdf

Redecker, C., Ala-Mutka K., \& Punie, Y. (2010). Learning 2.0 - The impact of social media on learning in Europe: POLICY BRIEF. Luxembourg: Office for Official Publications of the European Communities.

Robazza, C. Macaluso, C., \& D’Urso, V. (1994). Emotional reactions to music by gender, age, and expertise. Perceptual and Motor Skills, 79(2), 939-944.

Robertson, A. (2017, December 16). Are you still using an RSS reader? Retrieved Sep, 12, 2019, from THE VERGE: https://www.theverge.com/2017/12/16/16780356/rss-reader-feedly-news-sources-poll

Glotzbach, R. J., Mohler, J. L. \& Radwan, J. E. (2009). Really simple syndication (RSS): An educational approach. Journal of Interactive Media in Education (3), 13.

Ronfeldt, M., Farmer, S.O., McQueen, J.A. K., \& Grissom. (2015). Teacher collaboration in instructional teams and student achievement. American Educational Research Journal, 52 (3), 475- 514.

Roodt, S. \& Peier, D. (2013). Using youtube in the classroom for the net generation of students. Issues in Informing Science and Information Technology, 10, 473-487.

RSS Usage Statistics. (2019, 08). BuiltWith. Retrieved Sep, 12, 2019, from Trends, Intelligence and Internet Research: https:/trends.builtwith.com/feeds/RSS

Stäuble, B. (3- 4 February 2005). Using concept maps to develop lifelong learning skills: A case study. The Reflective Practitioner (p. Proceedings of the 14th Annual Teaching Learning Forum). Perth: Murdoch University.

Steffe, L. P. and J. E. Gale. (1995). Constructivism in education. Hillsdale, N.J.: Lawrence Erlbaum.

Sze-yeng, F. \& Hussain, R. M. R. (2010). Self-directed learning in a socio-constructivist learning environment. Procedia Social and Behavioral Sciences, 9, 1913 -1917.

Taylor , D.C. \& Hamdy , H . (2013). Adult learning theories: Implications for learning and teaching in medical education: AMEE Guide No. 83. Medical Teacher, 35(11), 1561 - 1572.

Terry K., \& Yolanda, E. (2015). Social media for lifelong learning. International Review of Psychiatry, 27(2), $124-132$.

The University of British Columbia (2019). The faculty of Education. Retrieved Sep, 30, 2019, from Master of Educational Technology: https://met.ubc.ca/courses/\#targetText=MET\%20courses\%20are\%20 designed $\% 20$ to,range $\% 20$ of $\% 20$ different $\% 20$ organizational $\% 20$ contexts. \& target Text $=$ To $\% 20$ assist $\% 20$ you $\% 20$ in $\% 20$ planning,three-year\%20projected\%20Course $\% 20$ Calendar.

Thompson, V. (2007). Talent shortage? How to win with what you've got. Super Vision, 68(2), 15- 17.

Topps, D., Helmer, J., \& Ellaway, R. (2013). YouTube as a platform for publishing clinical skills training videos. Academic Medicine, 88, 192 - 197.

Trust, T. (2015). Deconstructing an online community of practice: Teachers' actions in the Edmodo math subject community. Journal of Digital Learning in Teacher Education, 31(2), 73- 81.

Trust, T., Krutka G. D., \& Carpenter P. J. (2016). Together we are better: Professional learning networks for teachers. Computer \& Education 102(1), 15-34.

Visser, R. D., Evering, L. C., \& Barrett, D. E. (2014). \#TwitterforTeachers: The implications of Twitter as a self-directed professional development tool for K-12 teachers. Journal of Research on Technology in Education, 46(4), 396- 413. 
Vygotsky, L. (1978). Mind in Society: The development of higher mental functions. Cambridge, Mass: Harvard University Press.

Wenger, E. (1998). Communities of practice: Learning, meaning and identity. Cambridge, England: Cambridge University Press.

West, R.E., Wright, G., Gabbitas, B., \& Graham, C.R. (2006). Reflections from the introduction of blogs and RSS feeds into a pre-service instructional technology course. TechTrends, 50(4), 54-60.

Yardley, S., Teunissen, P.W. , \& Dornan, T. (2012). Experiential learning: Transforming theory into practice. Medical Teacher, 24, $161-164$. 